\title{
Employees' Job Satisfaction in Tertiary Level Hospitals
}

\author{
Abdullah SAHM ${ }^{1}$, Tamanna $N^{2}$, Jahan $I^{3}$
}

\begin{abstract}
Introduction: In a resource-limited and high burden disease setting, satisfied human resource is an asset in terms of high productivity, efficiency and quality care.
\end{abstract}

Objective: To evaluate and analyze the employees' job satisfaction at tertiary level hospitals and identify the important determinants for job satisfaction.

Materials and Methods: This descriptive study was done in two leading specialized private owned hospitals of Bangladesh during January 2011 to April 2011. A group of 200 employees were selected from both clinical $(60 \%)$ and non-clinical $(40 \%)$ staffs through systematic sampling method. Self-administered structured questionnaire was used keeping focus on organizational supportive activities, management employee relationship, gender discrimination and overall job satisfaction.

Results: Male and female participants were nearly equal, $75 \%$ female respondent was satisfied/highly satisfied on their job which was higher than male $(55 \%)(\mathrm{P}<0.005)$. Married participants and employees aged 31-40 years showed higher level of job satisfaction $(P<0.005)$. Forty Four percent respondent considered that salary was not at expected level and $47 \%$ opined that they could participate very often in decision making process. Two third respondents considered that they enjoyed freedom in their job and majority $(55 \%)$ admitted that they received praise for good work. All the respondents opined that they did not have any experience of sexual harassment. Univariate analysis was done to see the association between job satisfaction and other variables. Authority valued respondent's contribution $(P<0.005)$, satisfaction with salary and other benefits
$(P<0.005)$, superiors encourage employees about carrier development $(p<0.005)$, make feeling about importance of job $(P<0.005)$, receive praise for good work $(P<0.05)$, superior looks after the personal welfare $(P<0.05)$ and organization helps employee in their problem $(P<0.005)$ were found significantly associated with Job satisfaction.

Conclusion: To provide optimum health service by a health centre, all the staffs at all level, should be valued as an asset of the organization and their salary, participation and welfare should be properly looked after.

Key-words: Health staffs, job satisfaction, authority's support, authority-employee relationship.

\section{Introduction}

World's best possible machinery and best technology is likely to fail if they are not handled properly by well maintained and fully satisfied workforce. It is found that there is definite causal relationship between employees' job satisfaction and service quality ${ }^{1}$. Satisfied employees tend to be more productive and committed to their employers and a direct correlation has been shown between staff satisfaction and patient satisfaction in health care organizations ${ }^{2,3}$. The resulting demand for health care services and a relative shortage of some health care professionals makes it difficult for hospitals and other health care providers to provide consistently high levels of care. Health care administrators find themselves increasingly confronting the complex interrelationship between recruitment and retention of health care professionals and the quality of care and patient satisfaction experiences ${ }^{4}$. Different research has shown satisfaction predictors include working conditions, relationships

1. Lt Col Syed Abul Hassan Md Abdullah, MBBS, MPH, Diploma in HRM, ADGMS (Trg), Directorate General of Medical Services, Bangladesh Armed Forces, Dhaka 2. Dr. Nushrat Tamanna, MBBS, MPH, Associate Professor of Community Medicine, International Medical College, Gazipur 3. Lt Col Ishrat Jahan, MBBS, MPH, Commanding Officer, 15 Field Ambulance, Bangladesh Army. 
with co-workers and leaders, pay, promotion, security of employment, responsibility and working hours $9 a m-5 p m$. Because it affects not only quality of health service but also patients' satisfaction, the level of employees' job satisfaction which is very important for health care institutions. In Bangladesh, no significant study has been done about the employees' satisfaction scenario in tertiary hospitals where a highest standard of care is expected. The purpose of this study was to determine the level of employee's job satisfaction in tertiary hospitals and focused to address the significant determinants.

\section{Materials and Methods}

This descriptive cross sectional study was undertaken in two tertiary level hospitals of Dhaka, Bangladesh from January 2011 to April 2011. A group of 200 employees were selected from both clinical (120 respondents) and non-clinical (80 respondents) staffs. Sample size was $25 \%$ of total staff of hospitals. To make the sampling reliable, all the employees were graded into strata basing on their position, salary structure, education and job pattern. Then stratified random sampling method was used to select the participants to collect data and information. Confidentiality was duly ensured to all participants and Informed consent was obtained. Self-administered structured questionnaire was used keeping focus on organizational supportive activities, management employee relationship, gender discrimination and overall job satisfaction of employees. The questionnaire related to other than sociodemographic variables was close ended with five grade-point option. For the purpose of data analysis and validity of test, few variables were re-categorized into three grade-point option. During calculation of chi-square test, when more than $25 \%$ cell showed expected count less than 5, then Yeats correction (Fisher's Exact test) done. Level of significance assumed at $5 \%$ level $(\alpha=0.05)$. Ethical approval of the study was taken from Ibrahim Cardiac Hospital and Research Institute Bangladesh.

\section{Results}

Sociodemographic characteristics and their association: Among 200 respondents, 60\% represented from clinical group (Doctors, nurses, technician etc.) and rests were from different sectors of non-clinical group (admin and logistic staff). Most of the respondents $(85 \%)$ were married. Bulk of the respondents were from age group below 30 years (38\%). Majority $(55 \%)$ were having service length less than 5 years. Participants from Grade I and II (comprises with Doctors and senior admin staffs) were $33 \%$. Cross tabulation was done for different socio-demographic variables with perception of Job satisfaction level to reveal their association. $55.4 \%$ male participants showed satisfied/highly satisfied about job satisfaction which is lower than female counterpart (75\%) $(P<0.005)$. Satisfied perception among $31-40$ years age group was $81.1 \%(P<0.005)$. Married participants showed significantly higher satisfaction perception $(67.7 \%)(P<0.05)$. Among Grade III and IV employees, $71.4 \%$ and $69.4 \%$ respectively, put their remark as satisfied. Employees having 5-9 years service length, $68.3 \%$ of them reported as satisfied. No significant association was found between job satisfaction level with service length and Grade of appointment (Table-I).

Perception related to organizational supportive activities: About the participation in organizational decision making process, $47 \%$ opines that they got this scope often or very often, where as $25 \%$ thought it came sometimes and $46 \%$ respondent considered that their contribution was often or very often valued by the higher authority. Working environment in both the health centre appeared really friendly, $79 \%$ staffs considered that working environment was very often or often friendly. Regarding their salary and other benefits, $44 \%$ respondent considered that was not at all or rarely meets the satisfaction. Most of the staffs (67\%) considered that they enjoyed adequate freedom in the job. Findings showed that $79 \%$ participants were satisfied that their superior very often or often encouraged about their career development. This study showed that $79 \%$ respondents opined that there was no gender discrimination prevailing in their workplace. All the male and female participants $(100 \%)$ opined that they did not face any sexual harassment or they did not heard any incident of sexual harassment in their workplace (Table-II).

Perception related to Management-employee relationship: One third employee felt that their opinions sometimes counted by the authority, $55 \%$ respondent commented that they received praise from their superior for their good performance. Human values often or very often 
considered in work place opined by $66 \%$ participants. Around half $(49 \%)$ of staffs thought their career development or progress not at all or rarely discussed by the superiors, $23 \%$ respondent commented that their superior not at all or rarely gave any authority to them even they are fit for any particular job and $41 \%$ opined their highest satisfaction about superiors' concern regarding welfare, one fourth opposed that. Around $57 \%$ respondents opined that their superior often helped them to make their job more pleasant and $67 \%$ participants considered that their superiors were very often and often friendly and approachable (Table-III).

Association of employees' perception with Job satisfaction: Participants who opined that authority often or very often valued their contribution, $77.8 \%$ of them showed that they were satisfied or highly satisfied with their job $(P<0.005)$. Respondent who considered their salary was not at all or rarely satisfactory, only $50 \%$ of them satisfied with their present job.
But this was higher (72.2\%) among employees who were happy with their salary and benefits $(P<0.005)$. Job satisfaction level was clearly higher $(72.2 \%)$ among participants who considered superior encouraged about their career development than the group (only $33 \%)$ who did not think so $(P<0.005)$. Job satisfaction perception was six times higher $(77.6 \%)$ among participant who considered that organization gave feeling the importance of job than who did not agree $(P<0.005)$. Level of not satisfaction was five times higher $(38.1 \%)$ among the respondent who did not receive praise for good work than who received $(7.3 \%)$ that very often $(P<0.05)$. Participants who opined that their superiors very often looked after their personal welfare, $78 \%$ of them were satisfied which was significantly higher than who did not agree with this opinion $(46.1 \%)(P<0.05)$. Employees who commented that organization very often helped them in their problem, $81 \%$ of them were having highly job satisfaction perception $(P<0.005)$ (Table-IV).

Table-I: Socio-demographic characteristics and perception of Job satisfaction $(n=200)$

\begin{tabular}{|c|c|c|c|c|c|}
\hline \multirow[b]{2}{*}{ Characteristics } & \multicolumn{4}{|c|}{ Perception of Job satisfaction } & \multirow[t]{2}{*}{$\mathbf{P}$} \\
\hline & $\begin{array}{c}\text { Not at all/ not } \\
\text { satisfied } \%\end{array}$ & Neutral \% & $\begin{array}{c}\text { Satisfied/highly } \\
\text { satisfied } \%\end{array}$ & $\begin{array}{c}\text { Total } \\
n=200\end{array}$ & \\
\hline \multicolumn{5}{|l|}{ Sex } & \\
\hline Male & $14(12.5 \%)$ & $36(32.1 \%)$ & $62(55.4 \%)$ & $112(100 \%)$ & \multirow{2}{*}{$<0.005$} \\
\hline Female & $16(18.2 \%)$ & $06(6.8 \%)$ & $66(75 \%)$ & $88(100 \%)$ & \\
\hline \multicolumn{6}{|l|}{ Age of the respondent } \\
\hline Upto 30 years & $18(23.7 \%)$ & $22(28.9 \%)$ & $36(47.4 \%)$ & $76(100 \%)$ & \multirow{3}{*}{$<0.005$} \\
\hline $31-40$ years & $10(13.5 \%)$ & $4(5.4 \%)$ & $60(81.1 \%)$ & $74(100 \%)$ & \\
\hline$>40$ years & $2(4 \%)$ & $16(32 \%)$ & $32(64 \%)$ & $50(100 \%)$ & \\
\hline \multicolumn{6}{|l|}{ Marital status } \\
\hline Unmarried & $04(12.4 \%)$ & $14(43.8 \%)$ & $14(43.8 \% 0$ & $32(100 \%)$ & \multirow{2}{*}{$<0.05$} \\
\hline Married & $26(15.4 \%)$ & $28(16.7 \%)$ & $114(67.9 \%)$ & $168(100 \%)$ & \\
\hline \multicolumn{6}{|l|}{ Grade of Appointment } \\
\hline Grade I & $02(6.7 \%)$ & $14(46.7 \%)$ & $14(46.7 \%)$ & $30(100 \%)$ & \\
\hline Grade II & $06(16.7 \%)$ & $08(22.2 \%)$ & $22(61.1 \%)$ & $36(100 \%)$ & \\
\hline Grade III & $08(28.6 \%)$ & $00(0 \%)$ & $20(71.4 \%)$ & $28(100 \%)$ & \\
\hline Grade IV & $12(16.7 \%)$ & $10(13.9 \%)$ & $50(69.4 \%)$ & $72(100 \%)$ & \\
\hline Grade V & $02(5.9 \%)$ & $10(29.4 \%)$ & $22(64.7 \%)$ & $34(100 \%)$ & \\
\hline \multicolumn{6}{|l|}{ Duration of Job } \\
\hline$<5$ years service & $14(12.7 \%)$ & $28(25.5 \%)$ & $68(61.8 \%)$ & $110(100 \%)$ & \\
\hline $5-9$ years service & $16(19.5 \%)$ & $10(12.2 \%)$ & $56(68.3 \%)$ & $82(100 \%)$ & \\
\hline$>9$ years service & $00(0 \%)$ & $04(50 \%)$ & $04(50 \%)$ & $08(100 \%)$ & \\
\hline
\end{tabular}


Table-II: Perception related to organizational supportive activities $(n=200)$

\begin{tabular}{|l|c|c|c|}
\hline \multicolumn{1}{|c|}{ Factors } & Not at all or Rarely(\%) & Some-times (\%) & Often or Very Often(\%) \\
\hline Scope to participate in decision making & 28 & 25 & 47 \\
\hline Valuing by the authority about the contribution. & 20 & 34 & 46 \\
\hline Friendly work atmosphere. & 06 & 15 & 79 \\
\hline Satisfaction about salary \& other benefits & 44 & 20 & 36 \\
\hline Freedom of work. & 12 & 21 & 67 \\
\hline Encouragement about career development. & 12 & 09 & 79 \\
\hline Gender discrimination & 79 & 07 & 14 \\
\hline Facing sexual harassment. & 100 & 00 & 00 \\
\hline Hearing about incidence of sexual harassment & 100 & 00 & 00 \\
\hline In personal problem getting help from authority & 20 & 33 & 47 \\
\hline
\end{tabular}

Table-III: Perception related to Management-employee relationship $(n=200)$

\begin{tabular}{|l|c|c|c|}
\hline Factors & Not at all or Rarely (\%) & Some-times (\%) & Often orVery Often(\%) \\
\hline Counting individual opinion & 11 & 31 & 58 \\
\hline Praise for good work & 21 & 24 & 55 \\
\hline Human Values & 13 & 21 & 66 \\
\hline Appraisal about progress & 19 & 32 & 49 \\
\hline Having best friend in work place & 18 & 13 & 69 \\
\hline Getting information about activities of the org & 16 & 32 & 52 \\
\hline Getting authority to do job when found capable & 23 & 24 & 53 \\
\hline Looking the welfare by authority & 26 & 33 & 41 \\
\hline Making the job pleasant by supervisors. & 12 & 31 & 57 \\
\hline Friendly \& Approachable supervisors & 10 & 23 & 67 \\
\hline
\end{tabular}

Table-IV: Association of various job satisfaction determinants $(n=200)$

\begin{tabular}{|c|c|c|c|c|c|}
\hline \multirow[t]{2}{*}{ Events } & \multicolumn{4}{|c|}{ Perception of Job satisfaction } & \multirow[t]{2}{*}{$\mathbf{P}$} \\
\hline & Not satisfied/not so satisfied (\%) & Neutral (\%) & Satisfied/ highly satisfied (\%) & Total & \\
\hline \multicolumn{6}{|c|}{ Authority valued respondent's contribution } \\
\hline Not at all/ rarely & $18(45 \%)$ & $04(10 \%)$ & $18(45 \%)$ & $40(100 \%)$ & \multirow{3}{*}{$<0.005$} \\
\hline Sometimes & $12(17.6 \%)$ & $18(26.5 \%)$ & $38(55.9 \%)$ & $68(100 \%)$ & \\
\hline Often/very often & $00(0 \%)$ & $20(21.7 \%)$ & $72(78.3 \%)$ & $92(100 \%)$ & \\
\hline \multicolumn{6}{|c|}{ Satisfaction with salary and other benefits } \\
\hline Not at all/ rarely & $30(34.1 \%)$ & $14(15.9 \%)$ & $44(50 \%)$ & $88(100 \%)$ & \multirow{3}{*}{$<0.005$} \\
\hline Sometimes & $00(0 \%)$ & $12(30 \%)$ & $28(70 \%)$ & $40(100 \%)$ & \\
\hline Often/very often & $00(0 \%)$ & $16(22.2 \%)$ & $56(77.8 \%)$ & $72(100 \%)$ & \\
\hline \multicolumn{6}{|c|}{ Superiors encourage about carrier development } \\
\hline Not at all/ rarely & $12(50 \%)$ & $0416.7 \%)$ & $08(33.3 \%)$ & $24(100 \%)$ & \multirow{3}{*}{$<0.005^{*}$} \\
\hline Sometimes & $02(11.1 \%)$ & $10(55.6 \%)$ & $06(33.3 \%)$ & $18(100 \%)$ & \\
\hline Often/very often & $16(10.1 \%)$ & $28(17.7 \%)$ & $114(72.2 \%)$ & $158(100 \%)$ & \\
\hline \multicolumn{6}{|c|}{ Organization make feeling about importance of job } \\
\hline Not at all/ rarely & $12(75 \%)$ & $02(12.5 \%)$ & $02(12.5 \%)$ & $16(100 \%)$ & \multirow{3}{*}{$<0.005^{*}$} \\
\hline Sometimes & $06(18.8 \%)$ & $18(56.3 \%)$ & $08(25 \%)$ & $32(100 \%)$ & \\
\hline Often/very often & $12(7.9 \%)$ & $22(14.5 \%)$ & $118(77.6 \%)$ & $152(100 \%)$ & \\
\hline \multicolumn{6}{|c|}{ Receive praise for good work } \\
\hline Not at all/ rarely & $16(38.1 \%)$ & $04(9.5 \%)$ & $22(52.4 \%)$ & $42(100 \%)$ & \multirow{3}{*}{$<0.05^{*}$} \\
\hline Sometimes & $06(12.5 \%)$ & $16(33.3 \%)$ & $26(54.2 \%)$ & $48(100 \%)$ & \\
\hline Often/very often & $08(7.3 \%)$ & $22(20 \%)$ & $80(72.7 \%)$ & $110(100 \%)$ & \\
\hline \multicolumn{6}{|c|}{ Superior looks after the personal welfare } \\
\hline Not at all/ rarely & $16(30.8 \%)$ & $12(23.1 \%)$ & $24(46.1 \%)$ & $52(100 \%)$ & \multirow{3}{*}{$<0.05$} \\
\hline Sometimes & $06(9.1 \%)$ & $20(30.3 \%)$ & $40(60.6 \%)$ & $66(100 \%)$ & \\
\hline Often/very often & $08(9.8 \%)$ & $10(12.2 \%)$ & $64(78 \%)$ & $82(100 \%)$ & \\
\hline \multicolumn{6}{|c|}{ Organization helps employee in their problem } \\
\hline Not at all/ rarely & $10(25 \%)$ & $14(35 \%)$ & $16(40 \%)$ & $40(100 \%)$ & \multirow{3}{*}{$<0.005^{*}$} \\
\hline Sometimes & $10(15.2 \%)$ & $20(30.3 \%)$ & $36(54.5 \%)$ & $66(100 \%)$ & \\
\hline Often/very often & $10(10.6 \%)$ & $08(8.5 \%)$ & $76(80.9 \%)$ & $94(100 \%)$ & \\
\hline
\end{tabular}

${ }^{*}$ Fisher's Exact test 


\section{Discussion}

This descriptive study focused on to see the level of perception of job satisfaction and different determinants of job satisfaction in private owned tertiary level health care centres. To select the participants, stratified sampling method was followed and that helped to recruit the respondent from all categories of employee. Female participants showed significant higher satisfaction level than their male counterpart $(P<0.005)$. It may be due to, traditionally in our country women are less likely to change work and satisfied with minimum requirement. Job dissatisfaction is higher in younger age group ( $<30$ years aged) which is gradually decreased as age level increased $(P<0.005)$. It may be due to maturity of age has some influence on understanding of job satisfaction. Grade I Employee showed interesting opinion, 53.3\% participants of this group opined for either not satisfied or neutral. They are the highly skilled personnel and as they are career concern, so always look for better opportunity, that's why their satisfaction level was low, a study also shows that senior skilled staffs having lower satisfaction ${ }^{10}$.

Majority of the participants put their remarks on very often/often category in most of the events of organizational supportive activities, which in fact reflected their positive view towards the organization. Regarding their salary and benefit, $44 \%$ employee was not satisfied. Dissatisfaction with remuneration, specially in skilled organization like hospital is not uncommon in third world countries. If any hospital can seriously addresses these yardstick indicators of organizational support to its staffs, positive outcome will be always there. Authority's supportive gesture helps to develop feeling of belonging and accommodative attitude among employees. As result showed very low level gender discrimination and no single incident of sexual harassment, it indicated that both the organization was very strict regarding these issues and women staffs feels secure in their workplace. Different studies also support this findings ${ }^{11-14}$. As significant number of participants commented positive on management's attitude, so management-employee relation appeared happy and healthy. Other study ${ }^{15,16}$ also supporting the same findings. Job satisfaction in health care organization is related with many factors i.e. optimal work environment; the possibility to participate in decision making process; effective communication among staff and supervisors; and to be able to express freely one's opinion. The study result indicated few focus areas which need to be addressed to achieve desired employees' job satisfaction. Hospital staffs' satisfaction was observed to be associated with authority's recognition about employees contribution and organization's effort to make feeling about importance of job $(P<0.005)$. It suggested that if the organization properly evaluated employees' performance and valued their contribution for the organization, satisfaction level of employee will certainly increase. A study shows that Organizations that promote employee empowerment can help hospital staffs take a more active role in daily care decisions and enhance employee satisfaction ${ }^{17}$. When employees are more active in decision making in patient care, they feel more engaged which leads to higher satisfaction and lower turnover rates ${ }^{18}$. Salary and benefits is one of the key factors of employees' satisfaction and turnover. This study revealed that respondent who considered that their salary was not at the expected margin, their job satisfaction was poor $(P<0.005)$. Developing country like Bangladesh, in which health sector is struggling for adequate financial support, it is very difficult to satisfy all skilled manpower regarding salary and other benefits. As both the health centre of this study is private owned, so their financial capabilities is better than the Government hospital and for this dissatisfaction level was not that much high. Management and supervisors' encouraging attitude towards employees' career development $(P<0.005)$, praising for good works $(P<0.005)$ and positive gesture to address the personal welfare and problem $(P<0.005)$ was appeared a strong association with job satisfaction, a study ${ }^{19}$ supports that. When employees are more satisfied it helps to reduce stress, turnover, leaves of absence, and lower work-related disability and violence claims ${ }^{20-22}$, all of these factors help to increase the level of care given to patients.

\section{Conclusion}

Health care employees' job satisfaction is the key factor of a health center's efficiency. The result of this study will allow the management to understand the employees' perceptions and needs about their workplace and the organization. Job satisfaction can be ensured by supportive management attitude, balance salary and benefits, friendly working environment, 
participation in decision making process and organization's caring gesture about career and welfare related matter. A happy and satisfied workforce in any health centre can ensure better patient care as well as to achieve the goal of the organization.

\section{References}

1. Saari LM \& Judge TA. Employee attitudes and job satisfaction. Human Resource Management 2004; 43: 395-407.

2. Al-Almeri A. Job satisfaction and organizational commitment for nurses. Saudi Med J 2000; 21:531-5.

3. Tzeng HM. The influence of nurses' working motivation and job satisfaction on intention to quit: an empirical investigation in Taiwan. Int J Nurs Stud 2002; 39:867-78.

4. Karin N, Uvanney M, Bal C. The nurse retention, quality of care and patient satisfaction chain, International Journal of Health Care Quality Assurance 2001; 14(2):57-64.

5. Ellenbecker $\mathrm{CH}$, Porell FW, Samia L, et al. Predictors of home healthcare. Nurse Retention. J NursScholarsh 2008; 40:151-60.

6. Price M. Job satisfaction of registered nurses working in acute hospital. Br J Nurs 2002; 11:275-80.

7. Sourdif J. Predictors of nurses' intention to stay at work in a university health center. Nurs Health Sci 2004; 6:59-68.

8. Daehlen M. Job satisfaction and job values among beginning nurses: A questionnaire survey. Int J Nurs Stud 2008; 45:1789-9.

9. Hayes LJ, O'Brien-Pallas L, Duffield C, et al. Nurse turnover: A literature review. Int J NursStud 2006; 43:237-63.

10. Peltier J, DAHL A. The relationship between employee satisfaction and hospital patient experiences. Forum For People performance management and measurement: April 2009.
11. Magne N, Gulbrandsen PA, Reidun F, et al. Job satisfaction among Norwegian general practitioners; Scandinavian Journal of Primary Health Care 2005; 23: 198-202.

12. Atkins $P$, Marshall $M$, Stevenson B, et al. Happy employees lead to loyal patients, Journal of Health Care Marketing 1996; 16(4):14-23.

13. Freed, David H. Fifty-two effective, inexpensive ways to reward and recognize hospital employees, The Health Care Manager 1999; 18(1):20-8.

14. Schneider B, Snyder RA. Some relationships between job satisfaction and organizational climate.Journal of Applied Psychology 1975; 60:318-28.

15. Kivimaki M, kalimo R, Lindstorm K. Contributors to satisfaction with management inhospital ward. J Nurse Mang 1994; 2:229-34.

16.Love JE. A study of the relationship between perceived organizational satisfaction, and individual job satisfaction and adoptiveness in hospital laboratories. AM J Med Technol 1977; 43:1135-43.

17. Berlowitz DR, Young GJ, Hickey EC, et al. Quality improvement implementation in the nursing home, Health Services Research 2003; Part 1, 65-80.

18. Relf M. Increasing job satisfaction and motivation while reducing nursing turnover through the implementation of shared governance, CriticalCare Nursing Quarterly1995; 18(3):7-13.

19. Wagner, Sue Ellen. Staff retention: From "satisfied" to "engaged," Nursing Management 37 2003; 3:24-9.

20. Joel H, Dennis JS, Scott JB, et al. The impacts of high-involvement work systems on staff satisfaction and service costs in veterans' health care, Academy of Management Proceedings 2003; 3:1-6.

21. Joiner Therese A, Bartram T. How empowerment and social support affect Australian nurses' work stressors, Australian Health Review 2004; 28(1):56-64.

22. Landon BE, Reschovsky J, Blumenthal D. Changes in career satisfaction among primary care and specialist physicians, 1997_/2001. JAMA 2003; 289:442. 